\title{
Lágrimas de sangue: relato de um caso
}

\author{
Bloody tears:case report
}

\author{
Telma Gondim Freitas ${ }^{(1)}$ \\ Valter Justa ${ }^{(2)}$ \\ Eduardo J. C. Soares ${ }^{(3)}$
}

\begin{tabular}{|c|}
\hline \multicolumn{1}{|c|}{ RESUMO } \\
\hline $\begin{array}{c}\text { Os autores relatam o caso de uma paciente que apresentou lágri- } \\
\text { mas de sangue. Após ampla investigação diagnóstica nenhuma causa } \\
\text { orgânica para o fenômeno foi encontrada. É abordado o diagnóstico } \\
\text { diferencial desta condição clínica. }\end{array}$ \\
\hline
\end{tabular}

Palavras-chave: Lágrimas de sangue.

\section{INTRODUÇÃO}

Fenômeno clínico raro, as lágrimas de sangue constituem, indubitavelmente, uma das queixas oftalmológicas mais incomuns e alarmantes.

$\mathrm{Na}$ literatura existem poucas referências sobre o assunto. O objetivo deste trabalho é relatar o caso de uma paciente que apresentou lágrimas de sangue e familiarizar o oftalmologista para o diagnóstico diferencial desta condição.

\section{DESCRIÇÃO DO CASO}

SNSC, 16 anos, feminina, branca, estudante. Procurou o serviço com queixa de perda de sangue vivo pelo olho esquerdo há 3 meses, algumas vezes correlacionada com o período menstrual.

Ao exame oftalmológico encontrou-se acuidade visual de 20/20 em AO com correção (AO Esf. + 1,50). O exame do fundo do olho não mostrou alterações. A pressão intra-ocular era de $12 \mathrm{mmHg}$ em AO. A biomicroscopia do segmento anterior: não evidenciou alterações no $\mathrm{OD}$; no $\mathrm{OE}$ foi observada a presença de lágrimas sangüinolentas que surgiram após iniciada a consulta (Fig. 1).

A paciente foi submetida aos seguintes exames na tentativa de elucidação diagnóstica:

Exames clínicos otorrinolaringológico, ginecológico e vascular normais.

Tomografia computadorizada não revelou qualquer anormalidade orbitária.

Laparoscopia e ultra-sonografia pélvica normais (afastada endometriose pélvica).

Exame histológico dos fundos de saco conjuntivais feito em segmento da mucosa obtida mediante ressecção de elipse de conjuntiva no fórnice conjuntival superior: afastada a presença de endometriose conjuntival; plexo vascular mais rico que o natural, apresentando alguns vasos varicosos.

Pesquisa hematológica: afastada a possibilidade de discrasia sangüínea.

Médico oftalmologista do Centro Visual do Ceará. Fortaleza-CE.

(3) Médico oftalmologista da Policlínica Oftalmológica. Belo Horizonte - MG. 


\section{ANÚNCIO}




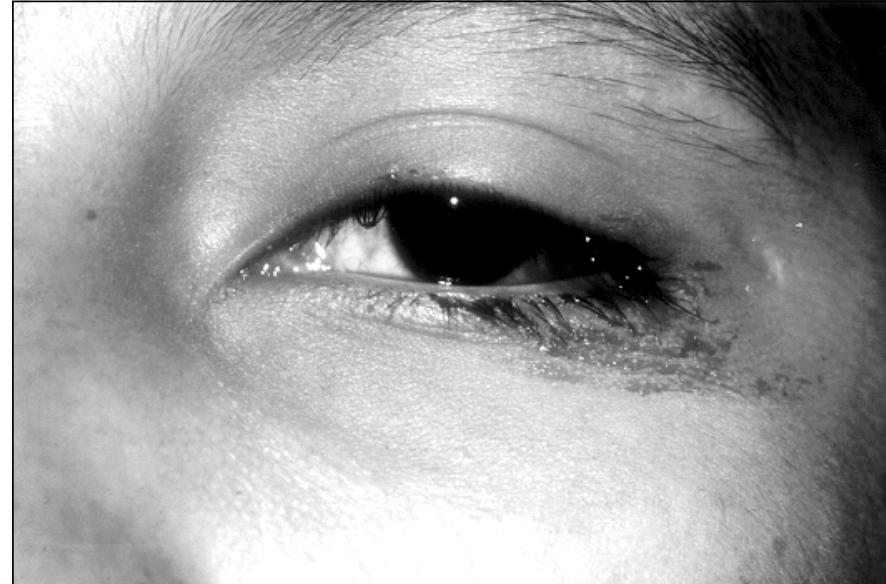

Fig.1 - Lágrimas sangüinolentas no OE.

\section{COMENTÁRIOS}

Lágrimas de sangue constituem um fenômeno raro. Seu diagnóstico diferencial inclui tumores vasculares conjuntivais, anemia severa, icterícia, telangiectasia hemorrágica hereditária, tumores da glândula lacrimal, endometriose conjuntival, menstruação vicariante, manipulação ocular, epistaxe com regurgitação através do sistema de drenagem lacrimal ${ }^{1}$; tumores do saco lacrimal ${ }^{2}$; granuloma piogênico ${ }^{3}$; melanoma conjuntival ${ }^{3}$; hemofilia e outras coagulopatias, distúrbios grosseiros do sistema nervoso autônomo e Síndrome de Goltz ${ }^{4}$, manipulação cirúrgica para expressão folicular em tracoma, tratamento conjuntival com nitrato de prata ${ }^{5}$. Bonavolantá e
Sammartino ${ }^{6}$ atribuíram a varizes orbitárias a causa de lágrimas de sangue.

No presente caso, embora tenha sido realizado extensa investigação diagnóstica, não detectamos nenhuma causa orgânica consistente que explicasse a existência das lágrimas de sangue. A suspeita quanto à presença de uma discrasia sangüínea rara não foi confirmada.

\section{SUMMARY}

The authors report a case of a female patient with bloody tears. No organic cause could be detected, despite extensive diagnostic investigation. A comment about the differential diagnosis is also presented.

Keywords: Bloody tears.

\section{REFERÊNCIAS BIBLIOGRÁFICA}

1. Duke Elder S, Stewart S, Leigh AG. Diseases of the Outer Eye. Conjunctiva. In: System of Ophthalmology. Vol 8. St. Louis, C.V. Mosby, 1964:37-9.

2. Brandt AM, Schachat AP, White RI. Ocular Manifestation of Hereditary Hemorrhagic Telangiectasia (Rendu-Osler-Weber Disease). Am J Ophthalmol 1989;107:642-6.

3. Duke-Elder S, Stewart S, Leigh AG. Diseases of the outer eye. Cornea and Sclera. In: System of Ophthalmology. Vol 8. St Louis, C.V. Mosby, $1965 ; 1180,1222$

4. Roy FH. Ocular Differential Diagnosis. Philadelphia, Lea and Febinger, 1984;71.

5. Ahluwalia BK, Khurana AK, Sood S. Bloody Tears (Haemolacria). Indian J Ophthalmol 1987;35(1):41-3.

6. Bonavolonta G, Sammartino. Bloody Tears from an Orbital Varix. Ophthalmologica 1981;182:5-6.

\section{Novidades na Internet:!!}

Agora no site CBO você tem disponível todas as informações na íntegra dos

Arquivos Brasileiros de Ditalmologia

http://w w w.cbo.com.br/abo 